\title{
CONHECENDO A ARARA-AZUL- GRANDE: CONFECÇÃO E APLICAÇÃO DE UM JOGO DIDÁTICO COMO PARTE DAS AÇÕES DE EDUCAÇÃO AMBIENTAL VISANDO A CONSERVAÇÃO DA ESPÉCIE
}

Flavia Torres Presti ${ }^{1}$

Talita Aleixo de Almeida ${ }^{2}$

Grace Ferreira da Silva ${ }^{2}$

Helder Elias da Silva ${ }^{2}$

Ludmila Pereira Conrado ${ }^{2}$

Letícia Cespede ${ }^{2}$

Tarcisio Magevski Rodrigues ${ }^{3}$

Mayla Barbirato ${ }^{3}$

Adriane Pinto Wasko²

Resumo: Atualmente, o mundo tem os "olhos" voltados à urgência de transformações em direção ao respeito pela vida e sustentabilidade. Assim, a utilização de estratégias de Educação Ambiental, visando reduzir risco de extinção de espécies animais pode contribuir enormemente para sua conservação. Entre as diversas aves nativas do Brasil, destaca-se a arara-azulgrande (Anodorhynchus hyacinthinus). O presente trabalho descreve a elaboração e aplicação de um jogo de tabuleiro com informações lúdicas sobre os riscos de extinção e propostas de conservação da arara-azul-grande, sendo direcionado a alunos do Ensino Fundamental I e II. Esse material de Educação Ambiental foi particularmente aplicado e avaliado na região do Mosaico de Carajás, no estado do Pará.

Palavras-chave: Jogo de tabuleiro; Arara-azul-grande; Educação Ambiental.

\footnotetext{
1 Instituto Federal do Paraná. E-mail: flavia.presti@ifpr.edu.br

2 Universidade Estadual Paulista. UNESP.

${ }^{3}$ Gerência de Meio Ambiente - GABAN, VALE.
} 


\section{Introdução}

A importância de uma abordagem atual baseada em sustentabilidade e respeito ao meio ambiente é incontestável. Desta forma, a Educação Ambiental surgiu diante da necessidade de se programar uma educação de caráter interdisciplinar, voltada para os problemas atuais e urgentes, que preparasse a população para viver e desenvolver-se em um mundo interdependente e em harmonia com as leis da natureza, e que abordasse de forma global a busca de soluções (BRONDANI; HENZEL, 2003). Nessa perspectiva, as práticas de Educação Ambiental visam a proteção dos ecossistemas, das espécies neles inseridas e do meio ambiente urbano. Em suma, a Educação Ambiental busca o entendimento das relações do homem com a natureza (TRAVASSOS, 2001).

Segundo a Conferência de Tbilisi (UNESCO, 1977), a Educação Ambiental é um processo permanente, no qual os indivíduos e a comunidade tomam consciência do seu meio ambiente e adquirem o conhecimento, os valores, as habilidades, as experiências e a determinação que os tornam aptos a agir individual e coletivamente e resolver os problemas ambientais. A aquisição desses conhecimentos é capaz de induzir mudança de atitude, uma vez que possibilita a construção de uma visão das relações do homem com o meio ambiente. Ao aproximar um indivíduo da sua realidade socioambiental, este poderá atuar como agente transformador na busca de soluções para os problemas ambientais mais urgentes vividos por sua comunidade.

Dentre os diversos problemas ambientais atuais, pode-se destacar a degradação ambiental e o tráfico de animais que levam muitas espécies à ameaça de extinção. Dentre essas espécies, está a arara-azul-grande (Anodorhynchus hyacinthinus). Essa ave, de plumagem azul cobalto e anéis dourados ao redor dos olhos e da mandíbula, é extremamente bela e altamente social (GUEDES et al., 2006), o que leva a ser muito explorada e, por isso, é considerada ameaçada de extinção (BIRDLIFE INTERNATIONAL, 2014). Além disso, é considerada uma espécie "guarda-chuva", contribuindo para a conservação de outras espécies e de todo meio ambiente onde vive. Ocupa três regiões distintas no Brasil, sendo a primeira delas localizada no sudeste do estado do Pará (leste da região amazônica e oeste de Altamira), a segunda na fronteira entre os estados do Maranhão, Piauí, Bahia, Tocantins, Goiás e Minas Gerais, e a terceira população encontra-se no Pantanal, compreendendo o sul do Mato Grosso, o noroeste do Mato Grosso do Sul, o norte do Paraguai e o leste da Bolívia (GUEDES et al. 2008; BIRDLIFE INTERNATIONAL, 2014). Dentre essas três regiões, somente no Pantanal existe um projeto de conservação dessa espécie de ave a longo prazo (Projeto Arara Azul), que mantém o monitoramento da população e realiza atividades de Educação Ambiental. Nesta região do país, as ações desse projeto conservacionista levaram à diminuição do tráfico destas aves, com especial destaque ao apoio da população local, que passou a ter maior consciência do valor de ver uma arara voando livre ao invés de confinada a uma gaiola. Com isso, a intenção inicial para conservação da espécie, que se referia à conscientização da população para deixar o animal livre, passou a focar-se na preservação do seu ambiente natural. Assim, Guedes (2004) afirma que o envolvimento da Revbea, São Paulo, V. 12, № 2: 259-273, 2017. 
população local certamente é um dos fatores de maior sucesso na recuperação da espécie. Apesar destes resultados a favor da conservação das araras-azuisgrandes no Pantanal, nas outras áreas de ocorrência esta espécie encontra-se ainda bastante vulnerável, com populações formadas por um menor número de exemplares e que sofrem vários efeitos antrópicos (GUEDES, 2004; PRESTI et al., 2009).

Na região do Mosaico de Carajás no sudeste do Pará, uma das áreas de ocorrência da espécie, a agricultura e a pecuária são as atividades principais. Neste cenário, a manutenção das araras é dificultada, devido a queimadas constantes e ao pisoteio do gado. As queimadas, muito utilizadas para o manejo do pasto e para a limpeza da roça, acabam se espalhando e alcançando as partes com vegetação mais alta, incluindo as árvores onde se encontram os ninhos e os alimentos para as araras. Já o pisoteio do gado impede a germinação e o desenvolvimento de muitas espécies vegetais, incluindo aquelas que fazem parte da vida das araras, seja como alimento, seja como local de nidificação (SILVA, 2009). Desta forma, atividades de Educação Ambiental nas comunidades dessa região do Brasil podem representar uma ação importante para a conservação das araras-azuis-grandes e de seu ambiente natural. Nesse contexto, o presente trabalho teve como objetivo realizar atividades de Educação Ambiental na região de Carajás - PA, por intermédio da aplicação de um jogo didático, visando favorecer a conservação das araras-azuis-grandes, a ampliação da percepção da comunidade sobre essa espécie e gerar mudanças de atitudes e valores em relação ao meio ambiente.

\section{Descrição do Jogo de Tabuleiro}

O material didático elaborado refere-se a um jogo de tabuleiro que aborda aspectos da biologia da arara-azul-grande, relações inter e intraespecíficas, mecanismos que levam a espécie à extinção, incluindo conteúdos de Genética e ações para sua conservação (Figura 1). Este consiste em um tabuleiro com informações (Figura 1), cartas-perguntas contendo respostas de múltipla escolha ou abertas (Figura 2), um dado e peças individuais ("pinos") para cada jogador (Figura 3). Podem participar de dois a cinco jogadores e cada jogador terá uma peça específica. No tabuleiro, existem "casas" onde os jogadores, após jogar o dado, "andam" até a "casa" correspondente ao número tirado. Se cair na "casa" denominada de "?", o jogador deve pegar uma "carta" pergunta (Figura 2) e tentar respondê-la. Se acertar, anda mais uma "casa". Se não souber ou errar a resposta, este deve passar a vez para o jogador que estiver na "casa" mais à frente do tabuleiro e este terá a chance de tentar responder à mesma pergunta anterior. Se houver mais de um jogador na mesma "casa", estes decidirão quem irá responder por meio do jogo do dado aquele que tirar o número maior poderá responder primeiro. Quando o participante "andar" nas "casas" do tabuleiro, mesmo que este caia na "casa" denominada de "?" ou em uma "casa" com uma instrução, este não irá responder. A vez de jogar o dado será do próximo participante. Se este cair na "casa" com alguma instrução, deve segui-la. $\mathrm{Na}$ "casa" denominada

revista brasileira educação ambiental 
"chocando", o participante deve permanecer uma rodada sem jogar. Ganha o jogo quem chegar primeiro na área do tabuleiro denominada de CONSERVAÇÃO.

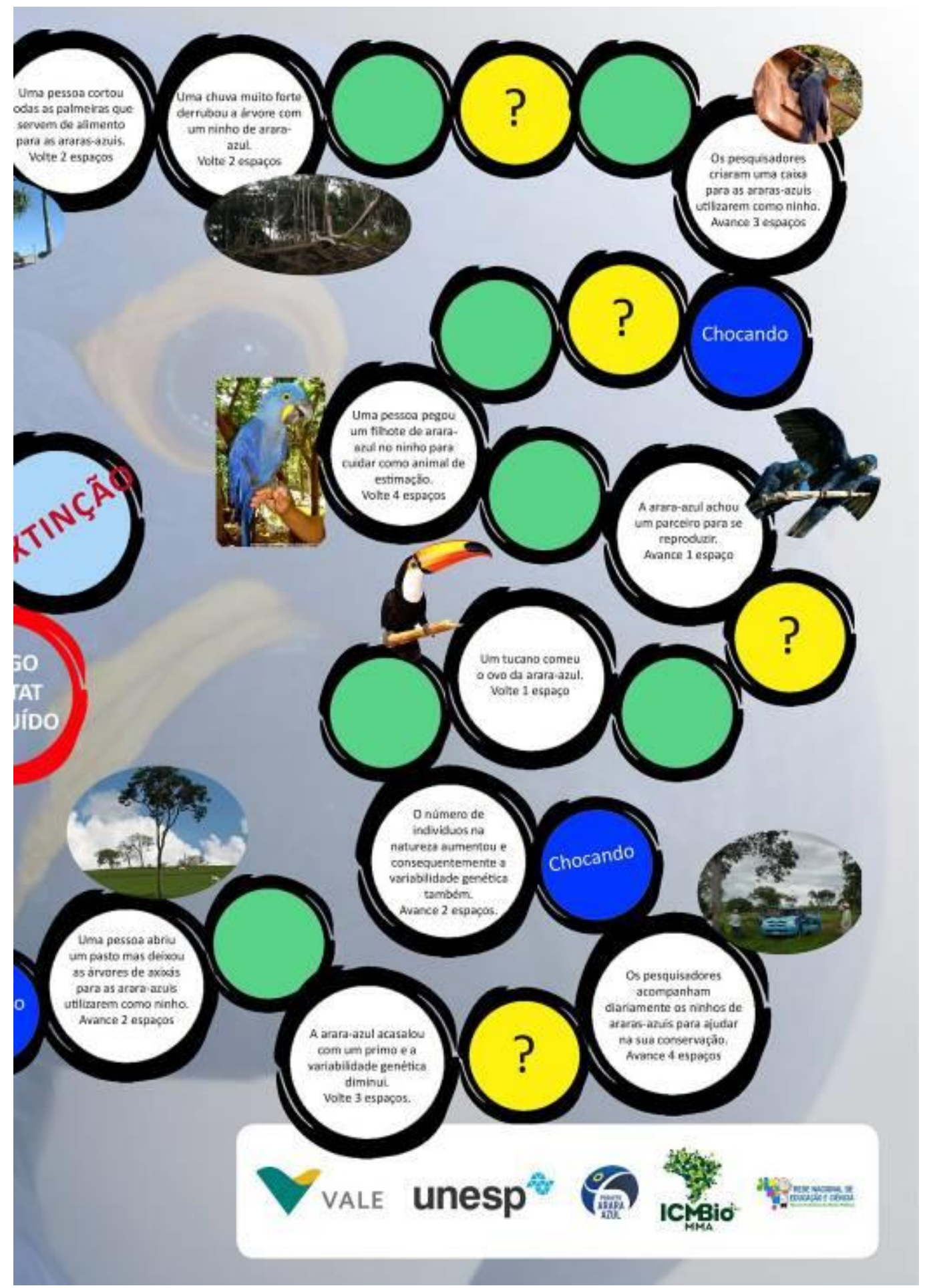

Figura 1: Tabuleiro do jogo sobre a arara-azul-grande.

Revbea, São Paulo, V. 12, № 2: 259-273, 2017. 

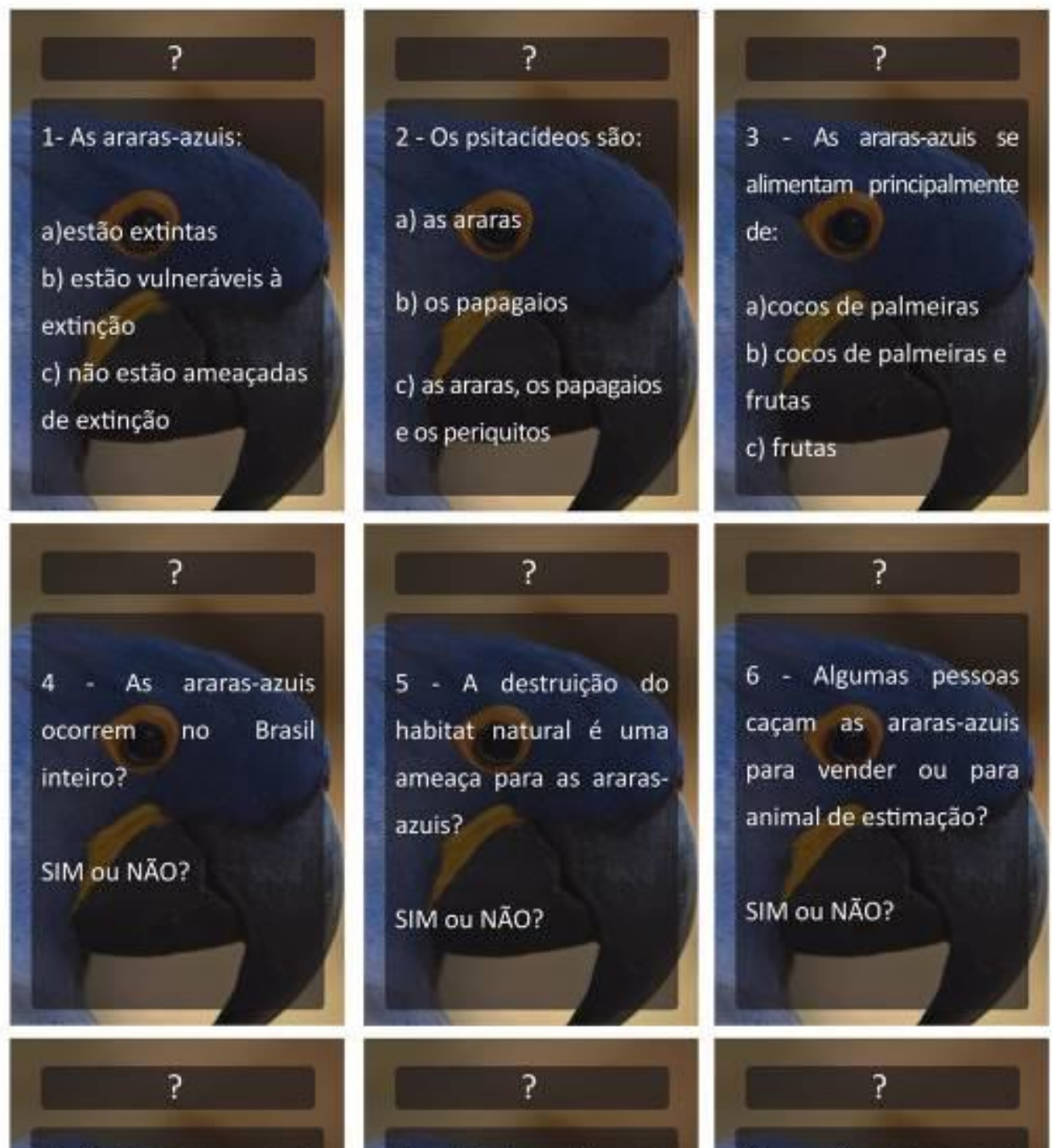

7 - Onde as araras-azuis costumam fazer seus ninhos na região do

Pará?

8 - Onde existe um programa permanente de monitoramento das araras-azuis?

a) árvore

a) Amazônia

b) paredões

c) qualquer buraco

b) Pantanal

c) Pará

9 - As araras-azuis quando encontram um parceiro (namorado) năo se separam mais (monogamia)?

SIM ou NÄO? 

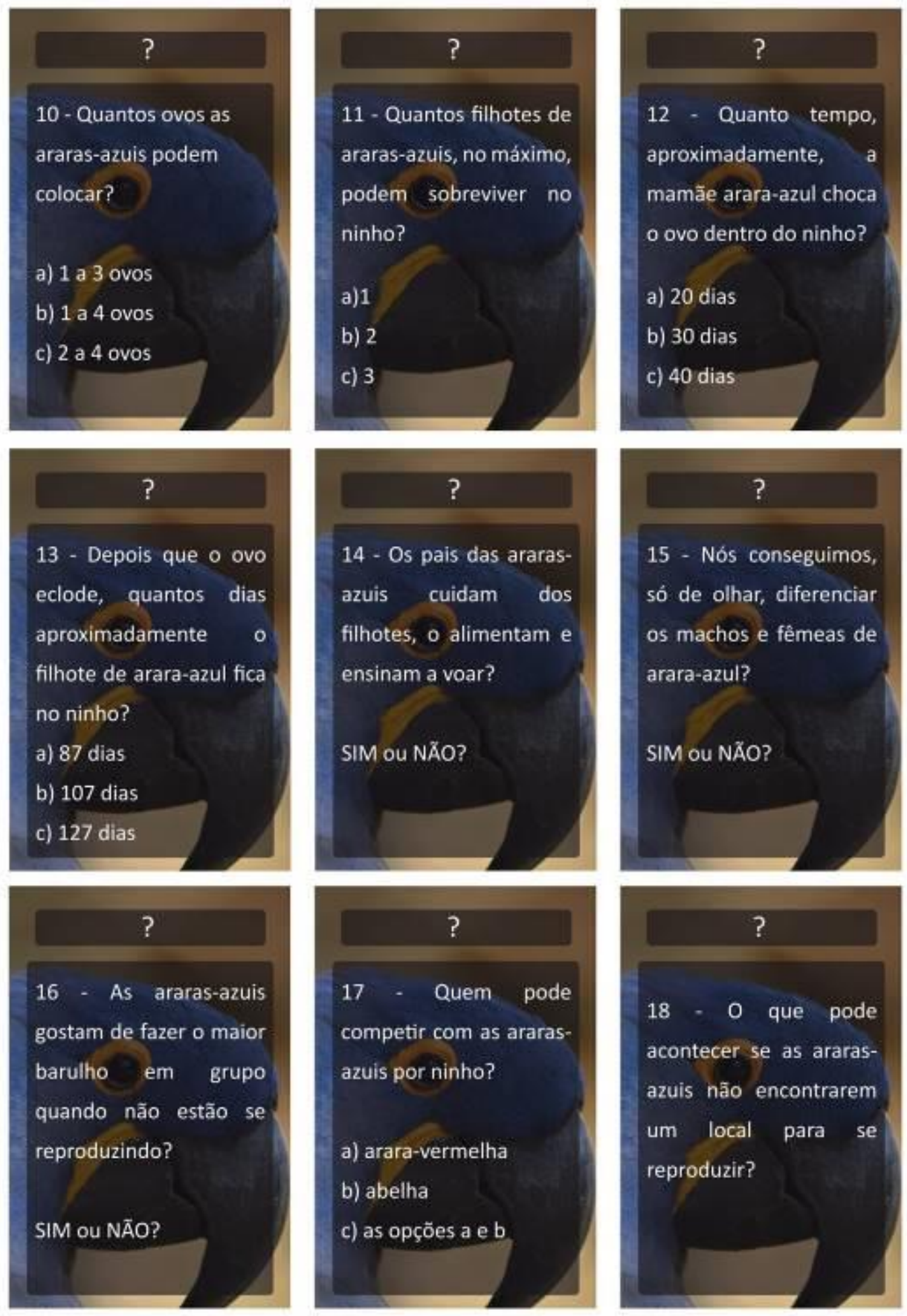

Continuação Figura 2

Revbea, São Paulo, V. 12, № 2: 259-273, 2017. 

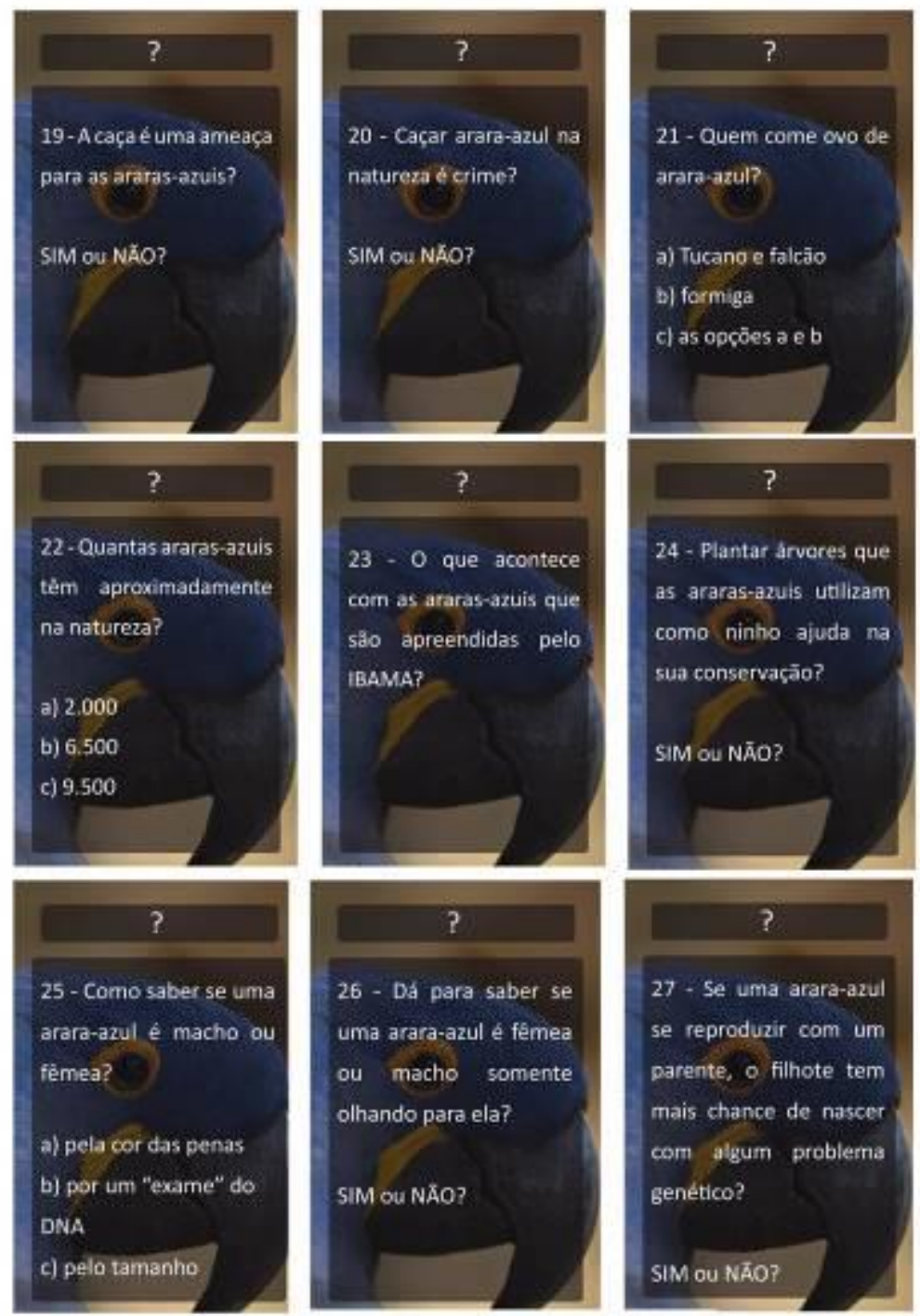

23 - O que acontece

com as araras-azuis que

stio apreendidas pelo

IBAMA?

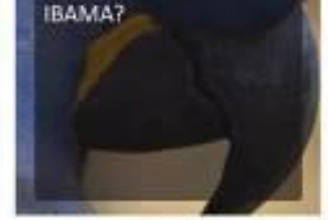

24- Plantar árvores que

as araras-azuis utilizam

como ninho ajuda na

sua conservaçāo?
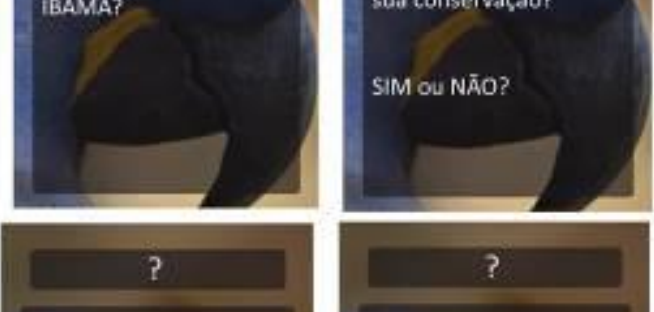

26 - Dá para saber se uma arara-azul é femea ou macho somente olhando para ela?

27 - Se uma arara-azul se reproduzir com um parente, o filhote tem mais chance de nascer com algum problema genético?

SIM ou NĀO?
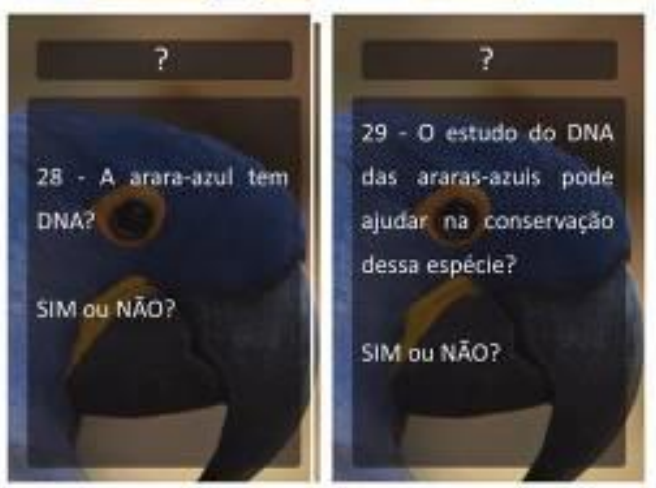

SIM ou NĀO?

Continuação Figura 2

Revbea, São Paulo, V. 12, № 2: 259-273, 2017.

revista brasileira de
educação
ambiental 


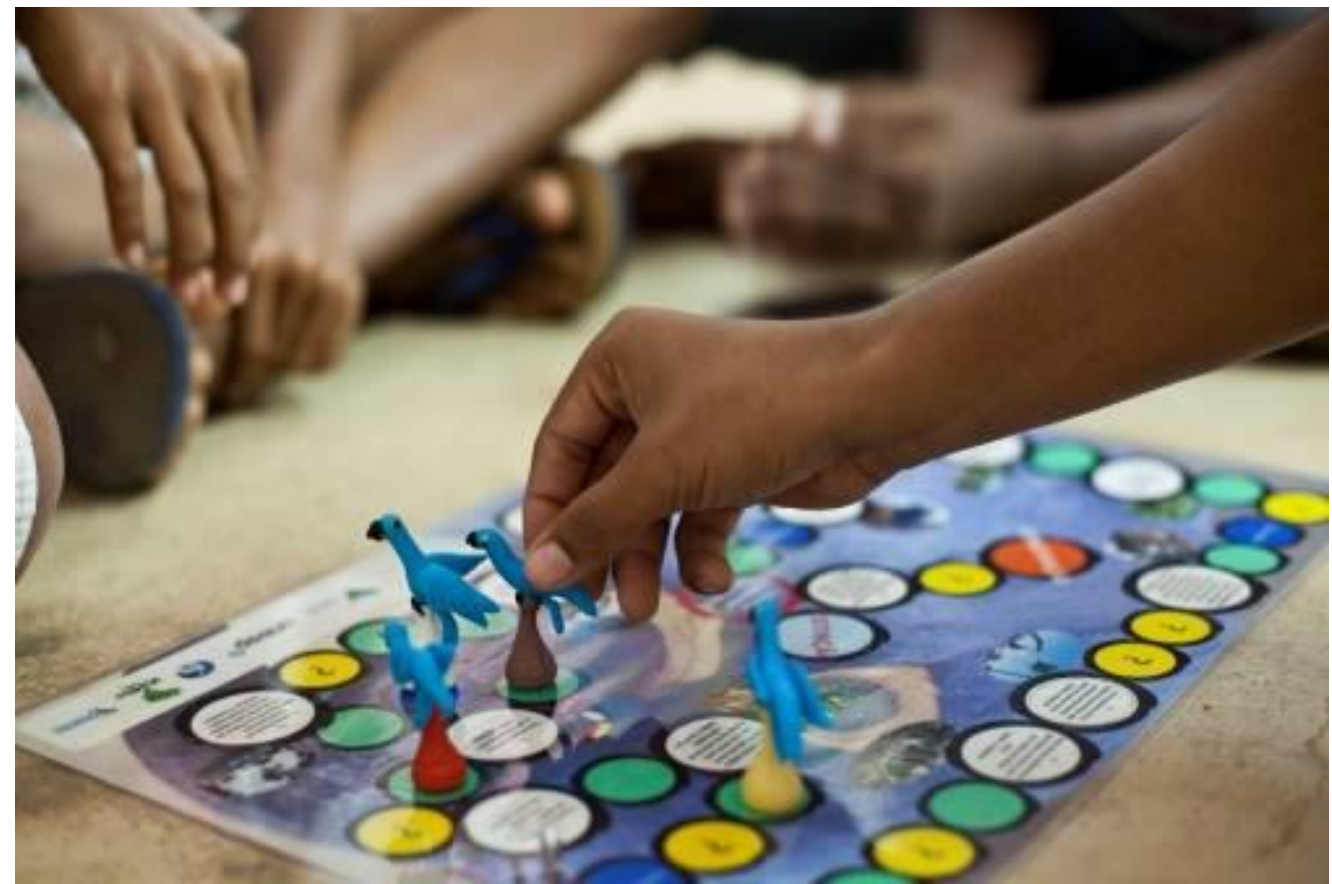

Figura 3: Imagem do jogo com suas peças ("pinos") para uso de cada jogador.

\section{Aplicação do jogo}

O tabuleiro do jogo foi confeccionado em papel reciclato $240 \mathrm{~g}$, no tamanho A3 e plastificado; as cartas foram impressas no mesmo papel em tamanho A4, também plastificado. As peças individuais ("pinos") foram elaboradas em biscuit, na forma de araras-azuis. A atividade educacional foi realizada em seis escolas municipais localizadas em duas cidades no sudeste do Pará, na região de Carajás: Parauapebas (EMEIF Crescendo na Prática, EMEIF Jorge Amado e EMEIF Paulo Freire) e Canaã dos Carajás (EMEIF Magalhães Barata, EMEIF Caros Henrique e EMEIF Odail Alves Ferreira). Foram atendidos 283 alunos, vinculados ao ensino fundamental I $\left(4^{\circ}\right.$ e $5^{\circ}$ anos) e ensino fundamental II $\left(6^{\circ}, 7^{\circ}, 8^{\circ}\right.$ e $9^{\circ}$ anos) (Tabela 1$)$. As atividades foram realizadas em março, abril, setembro e outubro de 2013 e tiveram aproximadamente 1 hora e meia de duração em cada turma. A Figura 4 mostra um dos grupos de alunos durante a realização da atividade educacional com o jogo elaborado. 


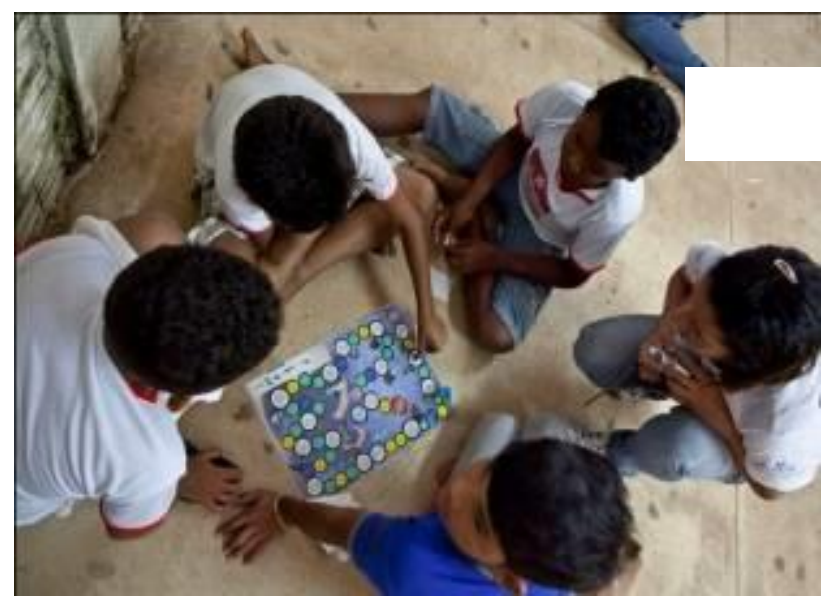

Figura 4: Alunos durante atividade de educação ambiental baseada na aplicação do jogo de tabuleiro.

Tabela 1: Nome da escola, data da atividade realizada e número de participantes por turma.

\begin{tabular}{ccc}
\hline Escola & Turma & $\begin{array}{c}\text { Número de } \\
\text { Participantes }\end{array}$ \\
\hline EMEIF Crescendo na Prática & $4^{\circ}, 5^{\circ}$ e $8^{\circ}$ Ano & 65 \\
EMEIF Magalhães Barata & $4^{\circ}, 5^{\circ}, 6^{\circ}, 7^{\circ}, 8^{\circ}$ e & 52 \\
& $9^{\circ}$ Ano & 29 \\
*EMEIF Odail Alves Ferreira & $4^{\circ}$ e $5^{\circ}$ Ano & 21 \\
*EMEIF Carlos Henrique & $4^{\circ}$ e $5^{\circ}$ Ano & 10 \\
EMEIF Carlos Henrique & $6^{\circ}$ e $7^{\circ}$ Ano & 14 \\
EMEIF Jorge Amado & $8^{\circ}$ Ano & 20 \\
*EMEIF Jorge Amado & $6^{\circ}$ Ano & 72 \\
EMEF Paulo Freire & $6^{\circ}, 7^{\circ}, 8^{\circ}$ e 9ㅇ Ano & 283 \\
TOTAL & & \\
\hline
\end{tabular}

*Escolas onde não foi possível a aplicação do questionário final

Antes da aplicação do jogo de tabuleiro, foi realizado um levantamento preliminar dos conhecimentos prévios dos alunos participantes das atividades, por meio do preenchimento de um questionário composto por nove questões de múltipla escolha (Anexo 1). Este questionário também serviu como incentivo à elaboração de novos questionamentos e discussão do tema abordado, por parte dos alunos participantes. Após a aplicação do questionário inicial, os mediadores das atividades de Educação Ambiental (alunos de mestrado da Universidade Estadual Paulista, Câmpus de Botucatu) conversaram com os alunos do ensino básico sobre os aspectos mais importantes sobre a biologia da arara-azul-grande, seu "status" de ameaça e responderam todas as perguntas levantadas pelos alunos sobre o assunto. Essa atividade foi primordial para contextualizar a importância e a aplicação do jogo para que este não fosse simplesmente "jogado por jogar". Além disso, esta explanação mostrou-se necessária para a compreensão do "antes" e do "depois", para que a atividade lúdica pudesse atingir seus objetivos didáticos (FLEMMING, 2004). 
As atividades de Educação Ambiental seguiram com a aplicação do jogo didático, seguindo as regras elaboradas para este e envolvendo grupos de 4 ou 5 alunos. Logo após a atividade do jogo, o questionário inicialmente preenchido pelos alunos foi re-aplicado. Este, além das mesmas nove questões de múltipla escolha, continha adicionalmente um espaço para críticas, sugestões e comentários. Este questionário final também incluía um espaço para a avaliação da atividade desenvolvida, como a discussão inicial sobre o tema abordado, o jogo de tabuleiro e os mediadores do jogo. Essa avaliação teve como objetivo procurar aspectos da atividade que poderiam ser melhorados.

\section{Avaliação da prática}

Embora não tenha sido possível obter o preenchimento do questionário final por todos os alunos participantes das atividades (Tabela 1), devido ao tempo despendido pela aplicação do jogo em si, a análise dos demais questionários e a comparação dos dados anteriores à aplicação do jogo e posteriores à aplicação deste mostraram-se suficientes para comprovar a eficiência das atividades educativas realizadas.

Nos questionários, foram abordadas questões sobre conhecimentos gerais em relação às araras-azuis-grandes, como: se os alunos conheciam e já viram as aves, se sabiam que se trata de uma espécie ameaçada de extinção e que é crime ambiental retirá-la da natureza, onde viram as araras-azuisgrandes, se conhecem a classificação das araras-azuis-grandes como psitacídeos, sua distribuição geográfica, as principais fontes de alimento e os possíveis fatores que podem levar ao desaparecimento da espécie.

Perguntas como: "Onde viram as araras-azuis" estimularam discussões interessantes quando os alunos apontavam ter visto na casa de alguém ou bares nas comunidades, voando livres na natureza ou ainda mantidas em zoológicos.

Um exemplo da quantidade de acertos com relação às informações apresentadas no questionário inicial e final é apresentado na Figura 5. O resultado mostra que a atividade composta da conversa informal sobre o tema somado à prática do jogo educativo levou ao aprendizado a respeito das araras-azuis-grandes, já que o número de acertos aumentou muito depois das atividades realizadas (Figura 5). Após a aplicação do jogo, questões como "Quais aves são classificadas como psitacídeos?" teve 95,2\% de acertos, "Em que árvore da região de Carajás as araras-azuis fazem os ninhos?" teve $79 \%$ de acertos e "Em quais regiões do Brasil a arara-azul pode ser encontrada?" e "Qual o principal alimento das araras-azuis?" tiveram $77,1 \%$ de acertos. A questão voltada para a conservação das araras-azuis ("O que podemos fazer para ajudar as araras-azuis?") apresentou como resposta uma associação entre conservação da espécie com preservação do habitat, combate à caça e venda ilegal, fiscalização e o diálogo perante a sociedade. 


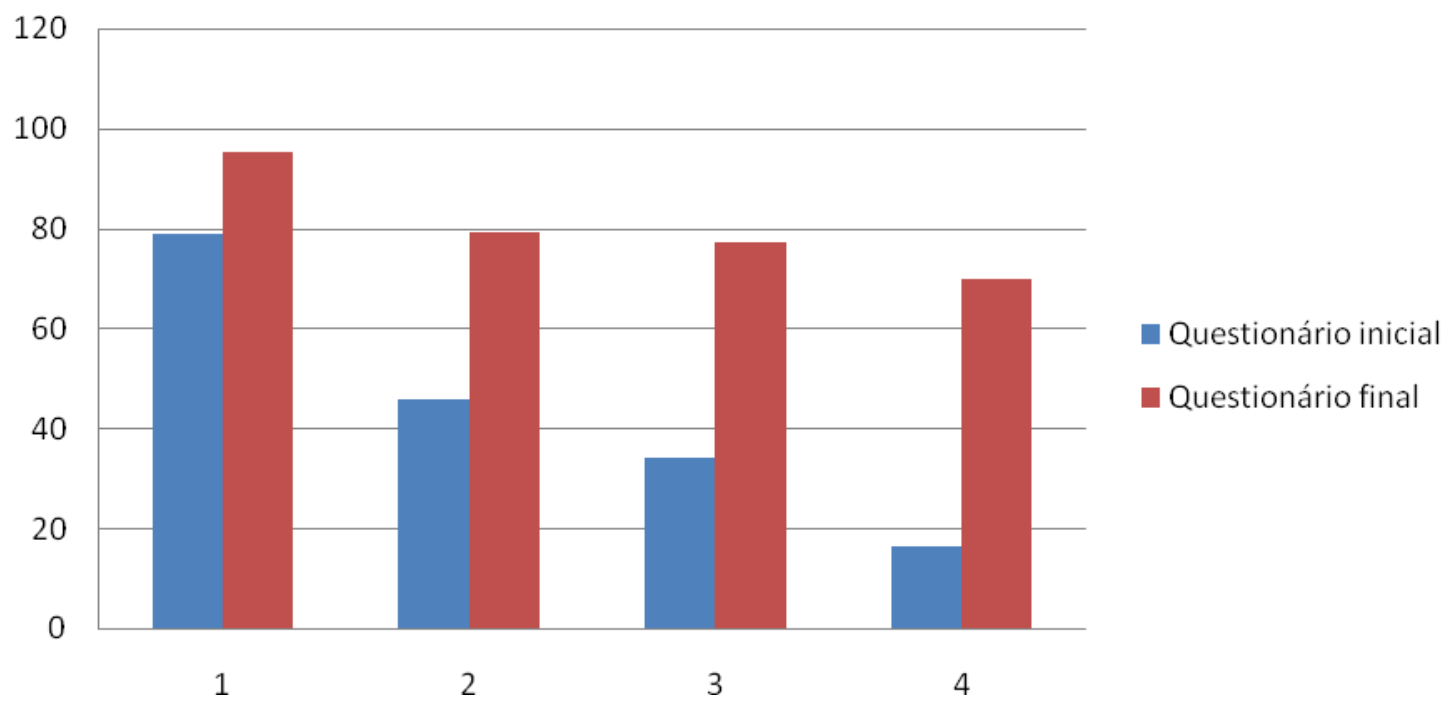

Figura 5: Número de acertos (\%) em relação ao questionário inicialmente e posteriormente preenchido, após a aplicação do jogo didático. Os números no gráfico referem-se às questões: 1 - "Quais aves pertencem ao grupo psitacídeo?"; 2 - "Em quais regiões do Brasil a arara-azul pode ser encontrada?"; 3 - "Qual é o principal alimento da arara-azul?"; 4 - "Em que árvore da Região de Carajás a arara-azul faz seu ninho?"

Todos os alunos que entregaram os questionários após a aplicação do jogo didático afirmaram que gostaram de aprender sobre a arara-azul-grande. A maioria dos alunos $(87,5 \%)$ classificou a atividade como ótima em relação à discussão do tema, ao jogo de tabuleiro, à atuação dos monitores e ao assunto abordado.

\section{Discussão}

Assim como Pedroso (2009), "acreditamos que a implementação de novas práticas educativas, dentre as quais se destaca o uso de estratégias de ensino diversificadas, possa auxiliar na superação dos obstáculos". A importância da variedade de instrumentos pedagógicos está, dentre outras coisas, em explorar as diferentes características de aprendizagem de cada indivíduo. E uma dessas abordagens pode ser o jogo didático. Muitos autores relatam o poder do jogo como método de ensino e aprendizagem (CARNEIRO, 1990; GOMES; FRIEDRICH, 2001), sendo uma alternativa para melhorar o desempenho dos estudantes pois se trata de uma atividade que mistura a aprendizagem de conteúdos com o lúdico. Os jogos divertem, motivam e facilitam a aprendizagem (CALADO et al., 2011). Além disso, o jogo permite uma maior socialização do grupo escolar, sendo também positivo para a aprendizagem (PINTO, 2009). Todos esses benefícios puderam ser observados na aplicação do jogo educativo das araras-azuis-grandes, uma vez que os alunos se divertiram e o resultado do questionário mostrou que houve apropriação do conhecimento por parte dos participantes. 
Além disso, existe outra vantagem desse tipo de abordagem no ensino, que é o de estimular outras habilidades, que não somente a busca pela aprendizagem. Enquanto joga, o aluno desenvolve a iniciativa, a imaginação, 0 raciocínio, a memória, a atenção, a curiosidade e o interesse, concentrando-se por longo tempo em uma atividade (FORTUNA, 2003). Os jogos são considerados educativos por abordarem diferentes habilidades cognitivas importantes para a construção da aprendizagem: resolução de problemas, percepção, criatividade, raciocínio rápido e lógico, contextualização dos assuntos, dentre outras.

Exemplos de jogos estão disponíveis na literatura e podem ser utilizados no ensino e em Educação Ambiental com sucesso. CALADO et al. (2011) elaboraram um jogo de cartas para contornar a dificuldade que estudantes apresentam em compreender conceitos associados às Briófitas e ROCHA et al. (2012) utilizaram um baralho para melhor compreensão de conceitos de Genética, matéria bastante abstrata para os alunos. Outro jogo didático sobre Água e Vida, foi utilizado por PINTO (2009) para estimular a preservação ambiental dos recursos hídricos. Ainda, BREDA; PICANÇO (2011) se utilizaram de jogo da memória, dominó, quebra-cabeça e jogo de tabuleiro para abordar diversas questões ambientais.

Aliando as potencialidades dos materiais didáticos lúdicos com os atuais objetivos da Educação Ambiental, acredita-se que a aplicação de jogos amparados por uma metodologia, conteúdos e objetivos específicos possa trazer contribuições significativas para este campo de estudo (BREDA \& PICANÇO, 2011) e a valorização de uma consciência ambiental nos participantes, transformando seu comportamento em relação ao ambiente em que vivem.

\section{Conclusão}

Durante a atividade didática realizada, foi possível observar a boa aceitação e interesse dos estudantes e a participação ativa destes no jogo e nas discussões a respeito do assunto abordado. Para atingir o objetivo da aprendizagem significativa e mudança de atitude, foi necessário planejar 0 recurso didático utilizado (jogo) dentro de uma proposta consistente e, por isso, os mediadores tiveram bastante cuidado em relação à contextualização do conteúdo por intermédio da conversa e discussão do tema abordado.

Ainda, observou-se que o jogo aplicado permitiu uma melhor compreensão do conteúdo abordado e despertou a curiosidade dos estudantes. Assim, foi possível concluir que é possível utilizar estratégias lúdicas divertidas para trabalhar assuntos de Educação Ambiental, em uma linguagem simples. Quanto maior o envolvimento dos alunos com a atividade lúdica, mais significativa é a aprendizagem. Com os resultados obtidos, podemos afirmar que os alunos passaram a ter uma visão diferente do que vem a ser a conservação da arara-azul-grande. 
Com este estudo, concluímos ainda que os professores e educadores podem implantar em suas aulas o jogo em questão, visando proporcionar aos alunos maior incentivo e interesse pelo tema de conservação das araras-azuisgrandes e com isso transformar a sala de aula em um lugar prazeroso e atrativo e que trate da realidade da comunidade em questão.

\section{Agradecimentos}

Ao Instituto Chico Mendes de Conservação da Biodiversidade (ICMBio), especialmente ao Frederico Drummond, Instituto Brasileiro do Meio Ambiente e dos Recursos Naturais Renováveis (IBAMA), Universidade Estadual Paulista (UNESP), Fundação do Instituto de Biociências (Fundibio), VALE e Mogno Meio Ambiente.

\section{Referências}

BIRDLIFE INTERNATIONAL. Anodorhynchus hyacinthinus. In: IUCN 2014. IUCN Red List of Threatened Species.Version 2014.1, 2014. Disponível em: www.iucnredlist.org. Acesso em: 20 jun. 2017.

BREDA, T.V.; PICANÇO, J.L. A educação ambiental a partir de jogos: aprendendo de forma prazerosa e espontânea. Anais do II SEAT - Simpósio de Educação Ambiental e Transdisciplinaridade. Goiânia, 2011. Disponível em: http://nupeat.iesa.ufg.br/uploads/52/original 2 EDUCACAO AMBIENTAL com JOGOS.pdf. Acesso em 15 jul. 2014.

BRONDANI, C.; HENZEL, M.E. Análise sobre a conscientização ambiental em escolas da rede municipal de ensino. São Paulo: FEMA, 2003. Disponível

em: http://www.sbecotur.org.br/revbea/index.php/revbea/article/view/1688. Acesso em 15 jul. 2014

CALADO, N.V.; COSTA, M.R.B.; CARDOSO, A.M.; PAES, L.S.; MELLO, M.S.V.N. Jogo didático como sugestão metodológica para o ensino de briófitas no ensino médio. Revista Amazônica de Ensino de Ciências 4: 92-101, 2011. http://www.revistas.uea.edu.br/download/revistas/arete/vol.4/arete v4 n062011-10.pdf. Acesso em 15 jul. 2014.

CARNEIRO, M.A.B. Jogando, descobrindo, aprendendo (depoimentos de professores e alunos do terceiro grau). São Paulo: Esc. Comunic. Artes USP. (Tese dout.), 1990.

FLEMMING, D.M. Criatividade e Jogos Didáticos. Anais do VIII Encontro Nacional de Educação Matemática, Recife, PE, 2004. Disponível em: http://www.sbem.com.br/files/viii/pdf/02/MC39923274934.pdf. Acesso em 15 jul. 2014.

FORTUNA, T.R. Jogo em aula. Revista do Professor, Porto Alegre, 19: 15-19, 2003. 
GOMES, R.R.; FRIEDRICH, M. A Contribuição dos jogos didáticos na aprendizagem de conteúdos de Ciências e Biologia. In: EREBIO, 1, Rio de Janeiro, 2001, 389-92.

GUEDES, N.M.R. Management and conservation of the large macaws in the wild. Ornitologia Neotropical 15: 279-283, 2004. Disponível em: https://sora.unm.edu/sites/default/files/journals/on/v015s/p0279-p0284.pdf.

Acesso em: 15 jul.2014.

GUEDES, N.M.R., MACIEIRA, A.C., BARBOSA, M.C.T. O uso do Sistema de informação geográfica (SIG) em trabalhos de conservação das araras azuis e vermelhas no Pantanal Sul Matogrossense. Ensaios e Cia 10: 167-179, 2006.

GUEDES, N.M.R., BIANCHI, C., BARROS, Y. Anodorhynchus hyacinthinus. In: Machado, A.B.M., G.M. Drummond \& A.P. Paglia (eds.) Livro Vermelho da Fauna Brasileira Ameaçada de Extinção. 2 vol. MMA - Ministério de Meio Ambiente. Brasília, DF, 2008.

PEDROSO, C.V. Jogos didáticos no ensino de biologia: uma proposta metodológica baseada em módulo didático. Anais do IX Congresso Nacional de Educação, EDUCERE, Curitiba, PR, 2009. Disponível em: http://www.isad.br/eventos/educere/educere2009/anais/pdf/2944 1408.pdf.

Acesso em 15 jul. 2014.

PINTO, L.T. O uso dos jogos didáticos no ensino de ciências no primeiro segmento do ensino fundamental da rede municipal de Duque de Caxias. Dissertação de Mestrado, Instituto Federal de Ciência, Educação e Tecnologia do Rio de Janeiro, Nilópolis, 2009. Disponível em: http://www.ifri.edu.br/webfm send/3039. Acesso em: 15 jul. 2014.

PRESTI, F.T., OLIVEIRA-MARQUES, A.R, SILVA, G.F., MIYAKI, C.Y., GUEDES, N.M. Notas sobre alguns aspectos da biologia da arara-azul (Anodorhynchus hyacinthinus) (Psittaciformes: Psittacidae) na região do Carajás, Pará. Atualidades Ornitológicas 151: 4-7, 2009.

ROCHA, L.N., LIMA, G.J.N.P., LOPES, G.S. Aplicação de jogos didáticos no processo ensino aprendizagem de genética aos alunos do $3^{\circ}$ ano do ensino médio do Centro de Ensino em Tempo Integral Franklin Dória do município de Bom Jesus- PI. REALIZE Editora, Campina Grande, PB, 2012. Disponível em: http://editorarealize.com.br/revistas/fiped/trabalhos/6351bf9dce654515bf1ddbd6 426dfa97.pdf. Acesso em 15 jul. 2014.

SILVA, S.M. Projeto Arara azul. In: DAMINELLI, R.M.; SILVA, S.M. Casos de sucesso na educação ambiental. IESDE Brasil S.A, Curitiba, 91- 106, 2009.

TRAVASSOS, L.E.F. Impactos gerados pela UHE Porto Primavera sobre o meio físico e biótico de Campinal, Presidente Epitácio, SP. Revista de Biologia e Ciências da Terra 1: 1, 2001. Disponível em: http://eduep.uepb.edu.br/rbct/sumarios/sumario v1 n1.htm. Acesso em: 15 jul. 2014.

UNESCO. Conferência de Tbilisi. 1977. Recomendação 1, parágrafos c, d e f. In: ESTADO DE SÃO PAULO. op. cit., p. 31. 


\section{ANEXO 1}

\section{Questionário inicial}

Você conhece a Arara-azul ?

( ) $\operatorname{Sim}$ Não ( )

Se sim, como ela é?

Você já viu uma Arara-azul ?
( ) Sim
Não ( )

Se sim, onde a viu?

Quais das aves abaixo são classificadas como psitacídeo?

( ) Araras, Galinhas e Tucanos

( ) Araras, Papagaios e Periquitos

( ) Galinhas, Papagaios e Tucanos

( ) Araras, Galinhas e Periquitos

Em quais regiões do Brasil a Arara-azul pode ser encontrada?

( ) Somente no Pará

( ) Somente no Pantanal

( ) No Pará, no Nordeste do país e no Pantanal

( ) Em todo o Brasil

Qual é o principal alimento da Arara-azul?

( ) Frutos de Palmeiras

( ) Frutos de Palmeiras e outras árvores

( ) Insetos que ficam nas Palmeiras

( ) Frutos e Legumes

Em que árvore da Região de Carajás a Arara-azul faz seu ninho?

( ) Coqueiro

( ) Axixá

( ) Qualquer Árvore

( ) Castanheira do Pará

A Arara-azul é uma espécie atualmente ameaçada de extinção?
( ) $\operatorname{Sim}$
Não ( )

Quais são os fatores que podem levar ao desaparecimento da Arara-azul?

( ) Destruição ambiental

( ) Caça para alimentação

( ) Caça para venda ilegal

( ) Todas as alternativas acima.

É crime pegar Araras-azuis na natureza?

( ) Sim Não ( ) 